\title{
FtsK functions in the processing of a Holliday junction intermediate during bacterial chromosome segregation
}

\author{
François-Xavier Barre, ${ }^{1}$ Mira Aroyo, ${ }^{1}$ Sean D. Colloms, ${ }^{1,3}$ Annett Helfrich, ${ }^{1}$ François Cornet, ${ }^{2}$ \\ and David J. Sherratt ${ }^{1,4}$ \\ ${ }^{1}$ Division of Molecular Genetics, Department of Biochemistry, University of Oxford, OX1 3QU, UK; ${ }^{2}$ Laboratoire \\ de Microbiologie et Génétique Moléculaire, Centre National de la Recherche Scientifique, Toulouse, France
}

In bacteria with circular chromosomes, homologous recombination can generate chromosome dimers that cannot be segregated to daughter cells at cell division. Xer site-specific recombination at dif, a 28-bp site located in the replication terminus region of the chromosome, converts dimers to monomers through the sequential action of the $\mathrm{XerC}$ and $\mathrm{XerD}$ recombinases. Chromosome dimer resolution requires that dif is positioned correctly in the chromosome, and the activity of FtsK, a septum-located protein that coordinates cell division with chromosome segregation. Here, we show that cycles of XerC-mediated strand exchanges form and resolve Holliday junction intermediates back to substrate irrespective of whether conditions support a complete recombination reaction. The C-terminal domain of FtsK is sufficient to activate the exchange of the second pair of strands by XerD, allowing both intra- and intermolecular recombination reactions to go to completion. Proper positioning of $\boldsymbol{d i f}$ in the chromosome and of FtsK at the septum is required to sense the multimeric state of newly replicated chromosomes and restrict complete Xer reactions to dimeric chromosomes.

[Key Words: Xer recombination; Holliday junction; chromosome segregation; FtsK]

Received August 31, 2000; revised version accepted October 23, 2000.

The faithful replication and segregation of chromosomes is necessary to ensure the efficient transmission of genetic information. The replication of chromosomes depends on homologous recombination, which is used to rescue replication forks that have broken or stalled when encountering barriers such as DNA lesions or blocked transcription complexes (Seigneur et al. 1998; Cox et al. 2000; McGlynn and Lloyd 2000; Michel 2000). Crossing over by homologous recombination can lead to sister chromatid exchanges (SCEs), odd numbers of which result in dimerization of the two newly replicated chromatids when the chromosomes or replicons are circular, as is often the case in bacteria. Plasmid or chromosome dimers compromise stable plasmid inheritance and chromosome segregation (Austin et al. 1981; Summers and Sherratt 1984; Blakely et al. 1991; Clerget 1991; Kuempel et al. 1991; Hendricks et al. 2000). Hence, most bacteria with circular genomes possess the specialized Xer sitespecific recombination system to convert chromosome and plasmid circular dimers to monomers (Recchia and

\footnotetext{
${ }^{3}$ Present address: Division of Molecular Genetics, IBLS, University of Glasgow, Glasgow G11 6NU, UK.

${ }^{4}$ Corresponding author.

E-MAIL sherratt@bioch.ox.ac.uk; FAX 44-1865-275297.

Article and publication are at www.genesdev.org/cgi/doi/10.1101/ $\operatorname{gad} .188700$.
}

Sherratt 1999). Xer site-specific recombination in Escherichia coli uses two recombinases of the tyrosine recombinase family, XerC (Colloms et al. 1990) and XerD (Blakely et al. 1993), which act on a 28-bp recombination site, dif, located in the replication terminus region of the chromosome (Blakely et al. 1991; Clerget 1991; Kuempel et al. 1991). When a chromosome dimer is present, a complete site-specific recombination reaction by XerCD introduces an additional SCE at dif, thus resolving the dimer into two monomers (Steiner and Kuempel 1998a).

Key questions about Xer site-specific recombination at dif concern how two dif sites separated by greater than 4 $\mathrm{Mbp}$ in a chromosome dimer can be efficiently synapsed together, and how the system is controlled to ensure resolution of chromosome dimers into monomers without risking the reverse reaction, which would create dimers from monomers. Xer-mediated recombination at dif, whether it be on the chromosome or on plasmids, depends on a functional homologous recombination system, apparently because complete Xer recombination reactions only occur in cells that contain chromosomal dimers (Steiner and Kuempel 1998b; Recchia et al. 1999). Furthermore, complete Xer recombination reactions require the C-terminal domain of FtsK (Recchia et al. 1999; Steiner et al. 1999), a septum-located protein that functions both in chromosome segregation and cell division 
(Begg et al. 1995; Diez et al. 1997; Draper et al. 1998; Liu et al. 1998; Wang and Lutkenhaus 1998; Yu et al. 1998a,b). These observations establish a link between Xer recombination, homologous recombination, and cell division. Finally, the 28-bp dif site is active only when located in a specific $30-\mathrm{kbp}$ region of the chromosome (the dif activity zone or DAZ), where it acts independently of any other specific sequence in that region, thus indicating the importance of the structural and spatial organization of the chromosome inside the cell for Xer recombination (Leslie and Sherratt 1995; Tecklenburg et al. 1995; Cornet et al. 1996; Kuempel et al. 1996; Perals et al. 2000).

Here, we show that Xer recombination, independently of any other cellular element, can form Holliday junctions (HJs) between dif sites, thereby potentially anchoring the two sister dif sites together immediately after their replication. HJ intermediates result from the exchange of a first pair of strands by XerC. They are unstable and are converted back to substrate in cycles of XerC-mediated strand exchanges. We also show that the membrane-bound and septum-located FtsK protein serves as a molecular antenna, which activates, through its $\mathrm{C}$ terminus, the exchange of the second pair of strands by the XerD recombinase when a chromosome dimer is present. These results help us understand how bacterial cells can integrate information at the cellular organization level to control enzymatic processes at the molecular level.

\section{Results}

The C-terminal domain of FtsK supports Xer recombination at dif

The 1329-amino acid FtsK protein contains three domains (Fig. 1A). The 200-amino acid N-terminal domain, domain 1, contains four transmembrane regions (Dorazi and Dewar 2000), localizes to the septum (Wang and Lutkenhaus 1998; Yu et al. 1998a) and is required for cell division (Diez et al. 1997; Draper et al. 1998). The 500-amino acid C-terminal domain, domain 3, is necessary for normal chromosome segregation (Liu et al. 1998; Yu et al. 1998b), at least in part because it is necessary for Xer recombination at dif (Recchia et al. 1999; Steiner et al. 1999). Cells lacking domain 3 form septate chains and filaments with aberrant and mispositioned nucleoids. Domain 3 is homologous with the C-terminal domain of SpoIIIE, a protein involved in DNA transfer from the mother cell to the prespore in Bacillus subtilis (Wu et al. 1995). Domains 1 and 3 are separated by a 600-amino acid linker region, domain 2 , which is not generally conserved in FtsK homologs. Overall, it is abundant in proline and glutamine and contains seven PQ-rich repeats of 10 amino acids.

To characterize further the functions of the three FtsK domains, we constructed FtsK truncations tagged with a Flag peptide to allow for immunodetection (Fig. 1A). The $f t s K$ derivatives were expressed from the arabinose promoter of plasmid pBAD24, the levels of expression being monitored by Western analysis. They were tested for Xer
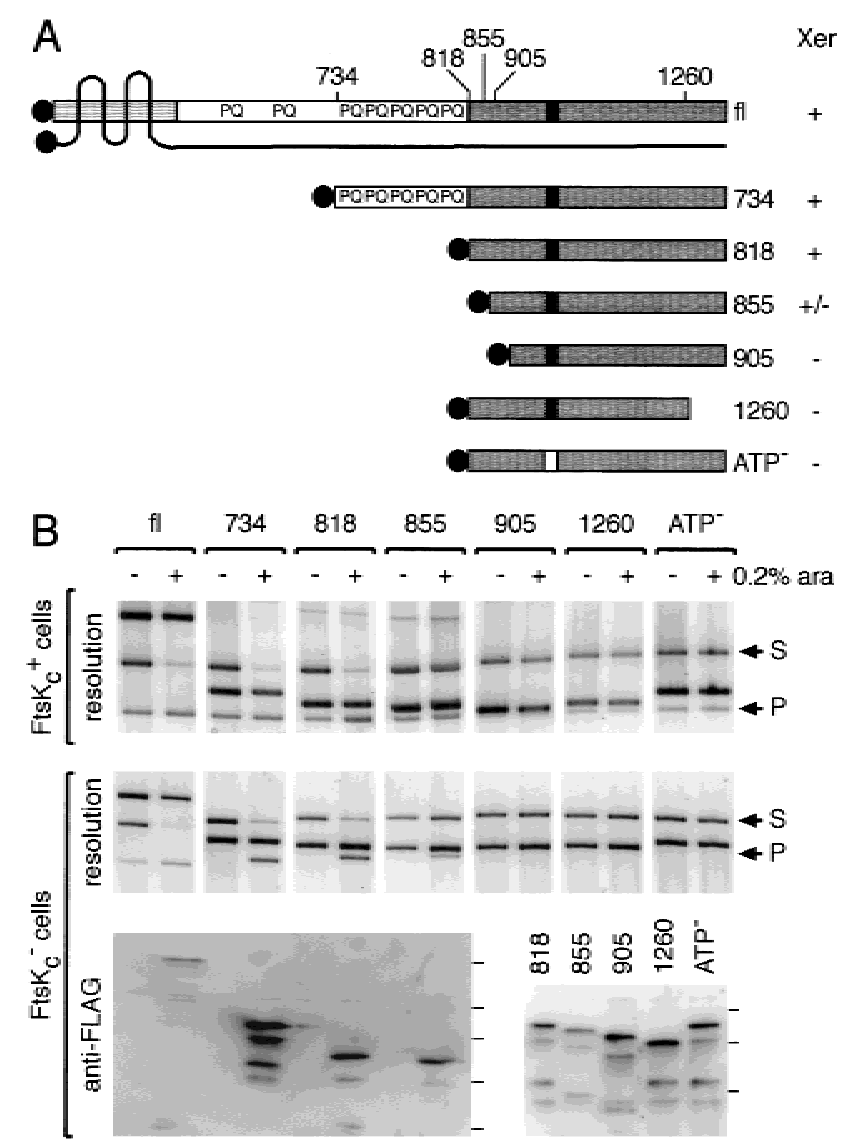

Figure 1. Minimal region of FtsK required for Xer recombination. (A) FtsK derivatives used in this study. The $\mathrm{N}$ terminal domain of FtsK, domain 1, is represented by a lightly shaded box, and the four putative transmembrane regions are shown as black lines crossing the protein. The extreme $\mathrm{N}$ terminus points toward the cytoplasm, as well as domain 2 and 3 of the protein. The C-terminal domain, domain 3 , is shown as a dark box, and the putative nucleotide binding site as a black rectangle. The Flag peptide is shown as shaded circles. The N-terminal $(734,818,855,905)$ and C-terminal (1260) amino acid of each protein are indicated on top of the full-length protein $(\mathrm{fl})$. The relative ability of each protein to support Xer recombination on plasmids is indicated by $+/-$ signs on the right of the diagram. $(B)$ Xer recombination between plasmid-borne dif sites in cells expressing FtsK deletions. ttsK $_{\mathrm{c}}{ }^{+}$(DS941) and $\mathrm{FtsK}_{\mathrm{c}}{ }^{-}$(DS9041) cells (as shown to the left of the gels) were transformed with the different ftsK expression vectors, as indicated along the top of the gels. Plasmid-containing cells were grown for $5 \mathrm{~h}$ in arabinose $(+$, $0.2 \%$ ara) or in glucose $(-)$. Recombination between the two dif sites carried by the substrate (S) leads to the formation of two smaller product circles, of which one can replicate $(\mathrm{P})$. The substrate and product bands are indicated by arrows to the right of the gels. The third band present in each lane is the ftsK expression vector. Expression of the FtsK derivatives was verified by Western blot analysis after resolution of the proteins on a $6 \%$ (fl, $734,818,855)$ or a $8 \%\left(818,855,905,1260, \mathrm{ATP}^{-}\right)$SDS-PAGE. Complete repression (-) was verified for $\mathrm{fl}, 734,818$, and 855 . The position of the protein molecular weight markers are indicated on the right of each blot and correspond from bottom to top to $32,47,67,83$, and $175 \mathrm{kD}$. The relatively low signal with fl may reflect a poorer transfer to the membrane. 
recombination between two dif sites carried by a plasmid (Fig. 1B). The full-length protein (fl), tagged at its $\mathrm{N}$ terminus, fully restored Xer recombination in cells that only expressed the $\sim 200 \mathrm{~N}$-terminal amino acids of FtsK needed for viability $\left(\mathrm{FtsK}_{\mathrm{c}}{ }^{-}\right)$. Indeed, the level of recombination was higher $(\sim 70 \%$ resolution) than that mediated by chromosomally located wild-type protein ( 30\% resolution), thereby indicating that normal levels of wild-type protein are limiting for Xer recombination as assayed on a plasmid, either because of FtsK amount and/or location. Note that in the absence of arabinose, a low level of resolution is observed in $\mathrm{FtsK}_{\mathrm{c}}{ }^{-}$cells carrying the fl plasmid derivative, presumably because of a low level of residual FtsK expression from the plasmid. Domains 1 and 2 were found not to be necessary for Xer recombination between dif sites: when overexpressed, the 734 and 818 FtsK derivatives, containing amino acid 734 and 818 to the normal $\mathrm{C}$ terminus, respectively, restored as much resolution as fl FtsK. The smaller 855 protein also showed activity although it was reduced compared with 818; this may be partly due to a lower level of protein. Further truncations of the $\mathrm{N}$ terminus (905) or of the C terminus (1260) of FtsK abolished Xer complementation, as did a lysine to alanine substitution at amino acid 997 in the putative nucleotide binding site $\left(\mathrm{ATP}^{-}\right)$. C-terminally tagged proteins showed a decreased activity compared with the $\mathrm{N}$-terminally tagged versions (data not shown). None of the FtsK derivatives that lacked the $\mathrm{N}$ terminus of the protein had any substantial dominant negative effect in cells expressing wild-type FtsK. This contrasts to a FtsK derivative containing all but the $65 \mathrm{C}$-terminal amino acids, which inhibited the action of the wild-type protein when expressed from a low-copy plasmid (Recchia et al. 1999). Thus, domain 1 or 2 of FtsK may be involved in the protein-protein interactions that allow a mutant protein to interfere with its wild-type counterpart, but the C-terminal domain of $\mathrm{FtsK}\left(\mathrm{FtsK}_{\mathrm{c}}\right)$ is sufficient in itself to allow an Xer recombination reaction to go to completion.

\section{Fts $_{c}$ is cytoplasmic}

As septum localization of FtsK has been proposed to be important for its function in Xer recombination (Recchia et al. 1999; Steiner et al. 1999), we checked the localization of the $\mathrm{fl}$ and 818 FtsK derivatives under similar expression conditions to those used in the plasmid resolution assay. To ensure a steady state level of expression of the proteins in exponentially growing cells, we grew $\mathrm{FtsK}_{\mathrm{c}}{ }^{-}$cells overnight in LB supplemented with $0.2 \%$ arabinose, diluted them in the morning with fresh medium, and grew them to an $\mathrm{OD}_{600}$ of $\sim 0.4 / \sim 25$ generations). Vizualization of the 818 derivative revealed a cytoplasmic distribution without any specific localization (Fig. 2A, 818). Similarly, the fl FtsK covered the whole membrane of the cells and failed to localize specifically to septum rings (Fig. 2A, fl). Thus, a failure to position $\mathrm{FtsK}_{\mathrm{c}}$ specifically at the septum does not prevent its function in Xer recombination.

The observed membrane coating by fl FtsK is likely due to the excess number of fl FtsK molecules over the number of potential FtsK attachment sites at the septum. To confirm this hypothesis, we checked the localization of $\mathrm{fl}$ under conditions of expression that more nearly correspond to the level of FtsK in wild-type cells, in which septum localization has been shown (Wang and Lutkenhaus 1998; Yu et al. 1998a). Indeed, the fl FtsK derivative tended to localize to specific loci that are reminiscent of septum rings in exponentially growing $\mathrm{FtsK}^{+}$cells when it was expressed for a shorter time (Fig. $2 \mathrm{~A}, 1 \mathrm{~h}$ induction). We could not detect the tagged proteins with lower, and even more physiological, levels of expression because the fluorescent signal decreased to background levels.

\section{Septum localization of Fts $K_{c}$ is required for normal cell morphology}

$\mathrm{FtsK}_{\mathrm{c}}{ }^{-}$cells form filaments and characteristic septate chains (Fig. 2B). Most of the phenotype of $\mathrm{FtsK}_{\mathrm{c}}{ }^{-}$cells can be accounted for by their inability to resolve chromosome dimers because $\mathrm{FtsK}_{\mathrm{c}}{ }^{-} \mathrm{RecA}^{-}$cells have a similar morphology to RecA- cells (Recchia et al. 1999). To test if expression of the C-terminal domain of FtsK could complement the chromosome segregation/cell division mutant phenotype of $\mathrm{FtsK}_{\mathrm{c}}{ }^{-}$cells, we examined the morphology of cells carrying the FtsK derivatives on plasmids in early exponential phase after growth in minimal medium containing different levels of arabinose. Expression of the FtsK derivatives was shown to increase with the amount of arabinose added as verified by Western analysis (data not shown). Cell morphology was restored to normal when fl FtsK was expressed at low concentration of arabinose $(0.025 \%)$. High levels of expression $(0.4 \%$ arabinose $)$ resulted in the loss of the septate chains but increased filamentation. Low level expression $(0.025 \%$ arabinose) of the 818 derivative did not complement the phenotype of $\mathrm{FtsK}_{\mathrm{c}}{ }^{-}$cells. On the contrary, we had the impression that some longer septate chains were present. A higher concentration of arabinose did not result in complementation and did not induce filamentation as was the case with the full-length protein /data not shown). Thus, cells expressing domain 3 independently of domain 1 or cells overexpressing the full-length protein, both of which result in the loss of the specific localization of domain 3 at the septum, displayed an abnormal morphology. We conclude that septum localization of $\mathrm{FtsK}_{\mathrm{c}}$ is important for its cellular role in chromosome segregation.

Transient HJ formation by XerCD at the chromosomal dif site

Xer site-specific recombination at dif can be viewed as a five-step process (Fig. 3A). After synapsis (Fig. 3A, i), a first pair of strand exchanges mediated by XerC (Fig. 3A, ii; Blakely et al. 2000; Hallet et al. 1999) leads to the formation of a $\mathrm{HJ}$ intermediate that needs to undergo a conformational change (Fig. 3A, iii) to be resolved by a pair of XerD-mediated strand exchanges (Fig. 3A, iv), before dissociation of the synaptic complex (Fig. 3A, v). 
A
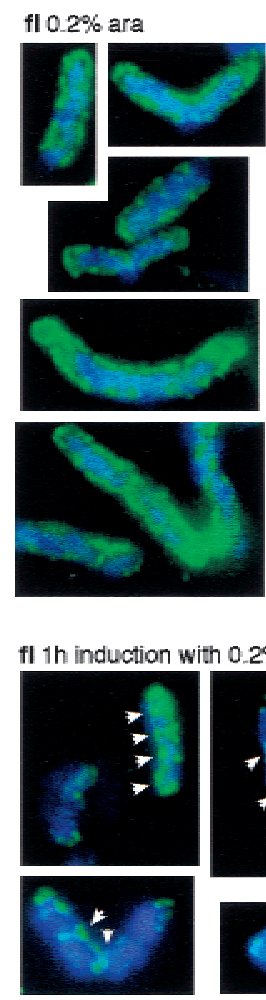
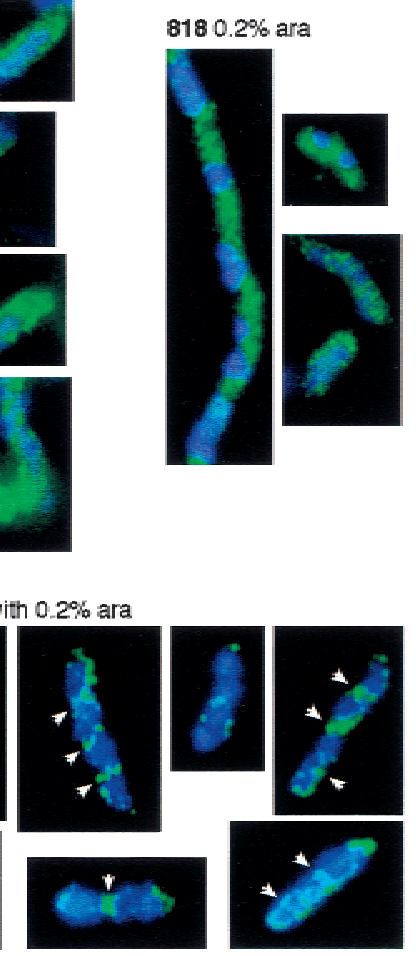

B
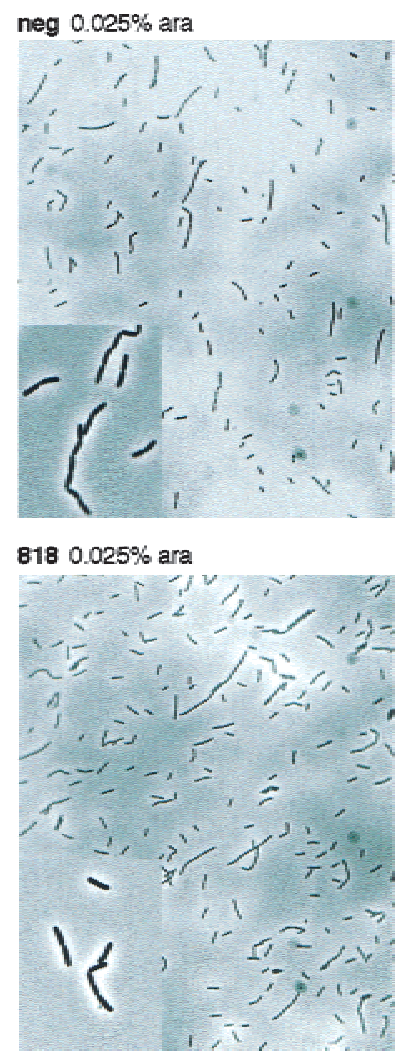

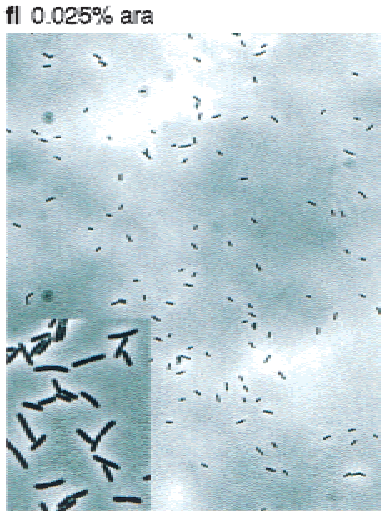

f $0.4 \%$ ara

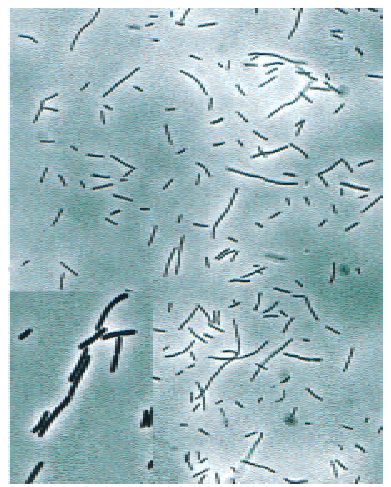

Figure 2. (A) Cellular distribution of $\mathrm{fl}$ and $818 \mathrm{FtsK}$ proteins. Induction with arabinose $(0.2 \%)$ was for $\sim 25$ generation in $\mathrm{FtsK}_{\mathrm{c}}$ (DS9041) cells (top) or for $1 \mathrm{~h}$ in $\mathrm{FtsK}_{\mathrm{c}}{ }^{+}$(DS941) cells (bottom). The localization of the DNA and of the FtsK proteins is shown in blue and green pseudocolors, respectively. White arrows indicate septum ring-like structures. $(B)$ Morphology of $\mathrm{FtsK}_{\mathrm{c}}{ }^{-}$cells expressing various amounts of $\mathrm{fl}$ or $818 \mathrm{FtsK}$ proteins or carrying a control expression vector (neg).

FtsK has been proposed to be necessary for Xer recombination at dif either by facilitating synapsis (Fig. 3A, i) or by facilitating a conformational change (Fig. 3A, iii) of the $\mathrm{HJ}$ intermediate that would reciprocally activate XerD and inactivate XerC (Recchia et al. 1999). To differentiate these two models, we monitored in vivo Xerdependent $\mathrm{HJ}$ formation at the chromosomal dif site. Earlier work that used a density label assay to measure Xer recombination at dif had failed to detect $\mathrm{HJ}$ intermediates (Steiner and Kuempel 1998a). As a consequence, we decided to use the highly sensitive technique of 2D gel electrophoresis, followed by DNA hybridization (Schwacha and Kleckner 1994, 1995). To prevent loss or branch migration of HJs, we cross-linked the DNA in cells by psoralen before isolation. In 2D gel electrophoresis, linear DNA migrates as an arc whereas $\mathrm{X}$ and $\mathrm{Y}$ branched structures migrate off the arc. Optimal separation between branched structures and their linear counterparts is obtained when their different arms are of equal length. As a consequence, EcoRV was used to digest the samples because it generates a $1.7-\mathrm{kb}$ fragment centred on dif (Fig. 3B). This same fragment was used as a probe for specific detection of the dif region.

Three spots $(a, b, c)$ could be detected that migrated as linear DNA in extracts from $\mathrm{Xer}^{+}, \mathrm{XerC}^{-}$, or $\mathrm{XerD}^{-}$ strains. The more intense spot (a) migrated as the ex- pected 1.7-kb fragment centred on dif. (b) and (c) migrated as a $2.5-\mathrm{kb}$ and a $6.3-\mathrm{kb}$ fragment, respectively, which correspond to partial digests. Those partial digests result from the specific inhibition of restriction enzymes by the presence of a cross-link at their cutting site (Barre et al. 2000), and therefore reflect the efficiency of crosslinking. A fourth and fainter fragment could be detected between (b) and (c) and is probably due to cross-hybridization of the dif probe with some other region of the genome. Two spots ( $\mathrm{d}$ and e) are clearly visible above the arc of linear molecules extracted from $\mathrm{Xer}^{+}$cells. Their sizes are in agreement with them being the expected 3.4-kb HJ at dif (d) and a 4.2-kb $\mathrm{HJ}$ (e) resulting from partial digest. No HJs were detected in $\mathrm{XerC}^{-}$or $\mathrm{XerD}^{-}$ cells, as expected because the presence of both recombinases is required for catalysis by either (Blakely et al. 1993). Thus, the HJs observed at dif in the $\mathrm{Xer}^{+}$strain result from the action of the Xer recombinases, and not from the action of other recombination systems.

A good approximation of the level of HJ-containing fragments in the psoralen-treated cell extracts can be obtained by quantitating the relative intensity of the $\mathrm{HJ}$ spot (d) to the intensity of the linear spot (a). We believe this value reflects the steady state level of HJs in exponentially growing cells, and therefore the equilibrium between the rates of $\mathrm{HJ}$ formation and resolution. A 

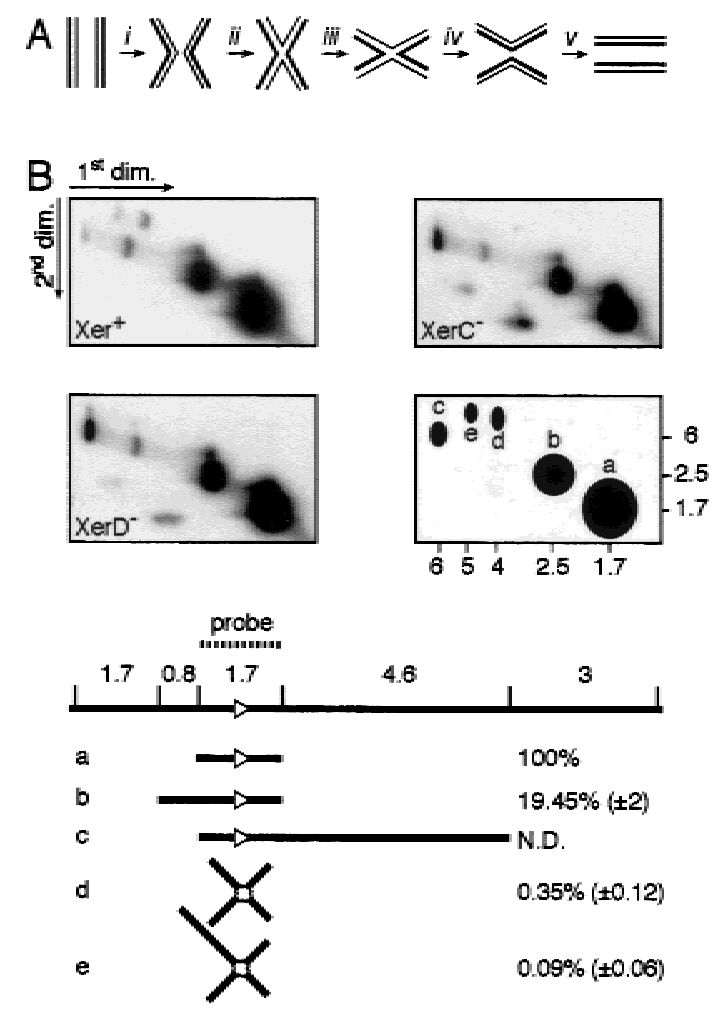
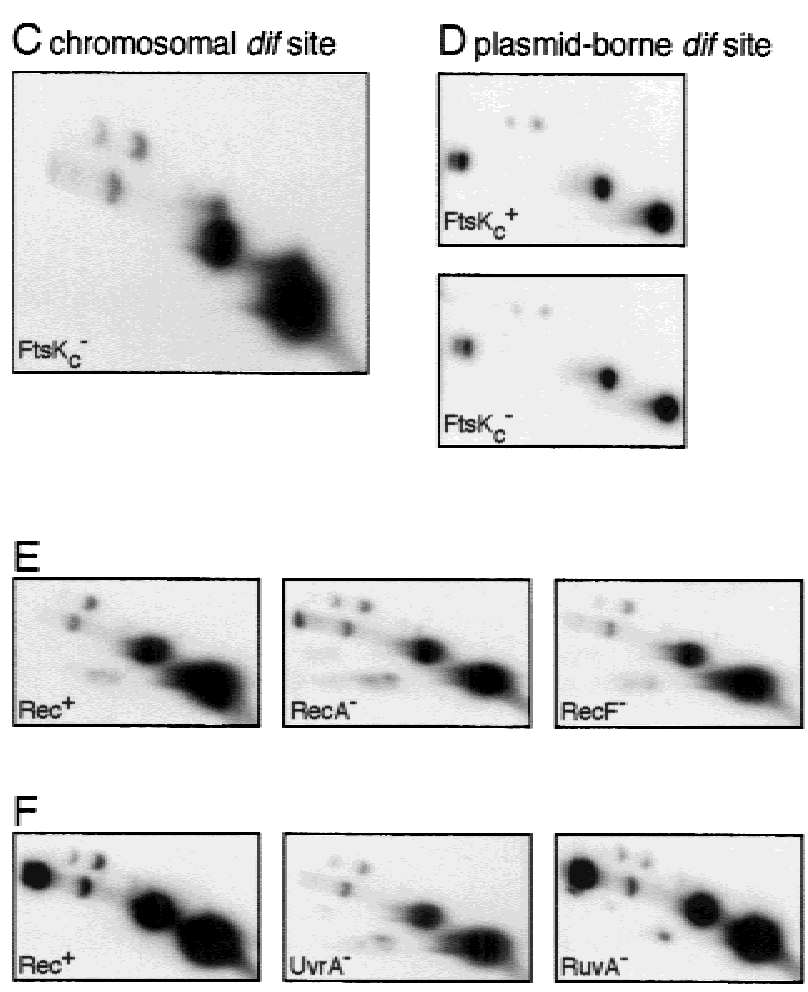

Figure 3. In vivo detection of $\mathrm{HJ}$ intermediates at the chromosomal dif site. $(A)$ The different steps of Xer site-specific recombination. (i) Synapsis; (ii) first pair of strand exchanges; (iii) HJ conformational change; (iv) second pair of strand exchanges; (v) dissociation. (B) Detection of HJs at dif in $\mathrm{Xer}^{+}$(AB1157), $\mathrm{XerC}^{-}$(DS8029), and $\mathrm{XerD}^{-}$(GR18) cells. EcoRV was used to restrict the DNA samples. A simplified scheme of the hybridization signals is shown along with molecular weights in kilobase pairs. Five spots were detected that correspond to expected linear $(\mathrm{a}, \mathrm{b}$, and $\mathrm{c}$ ) or joint ( $\mathrm{d}$ and e) molecules. The EcoRV restriction digest map of the dif region and the molecules that can be attributed to the $\mathrm{a}, \mathrm{b}, \mathrm{c}, \mathrm{d}$, and e spots are represented below the blots. The dif site is shown as a white triangle. The relative intensity of each spot to the intensity of spot (a) was calculated in $\mathrm{XerC}^{+} \mathrm{XerD}^{+}$cells. Numbers correspond to the mean and standard deviation of values from eight independent experiments. $(C) \mathrm{HJs}$ at the chromosomal dif site in FtsK ${ }_{\mathrm{c}}^{-}{ }^{-}$cells $\left(\mathrm{MA}^{2}\right)$. (D) $\mathrm{HJ}$ in $\mathrm{FtsK}_{\mathrm{c}}{ }^{+}(\mathrm{AB} 1157)$ and $\mathrm{FtsK}_{\mathrm{c}}{ }^{-}$cells carrying a multicopy plasmid with a single dif site. (E) HJs at the chromosomal dif site in Rec ${ }^{+}$ (AB1157), RecA- (GR19), and RecF- (DS941) cells. (F) HJs at the chromosomal dif site in $\mathrm{Rec}^{+}$(JJC40), UvrA- (N3137), and RuvA (JJC662) cells. The smeary bands below the arc of linear DNA in some of the gels are blotting artefacts and contain small amounts of the major DNA species from the linear arc.

mean value of $0.3 \%$ of $\mathrm{HJs}$ was obtained in wild-type cells.

\section{Fts $_{c}$ is not required for $\mathrm{HJ}$ formation by the Xer} recombinases at dif

We reasoned that if the $\mathrm{C}$ terminus of FtsK was implicated in synapsis, its absence would lead to a decrease in the level of HJs formed by XerCD at dif. In contrast, we observed as many HJs in DNA extracts from $\mathrm{FtsK}_{\mathrm{c}}{ }^{-}$cells as in DNA extracts from $\mathrm{FtsK}_{\mathrm{c}}{ }^{+}$cells (Fig. 3C). This was also true when we looked at a dif site carried by a plasmid (Fig. 3D). We conclude that FtsK $_{\mathrm{c}}$ is not needed for synapsis and for $\mathrm{HJ}$ formation by XerCD.

\section{Homologous recombination is not required for HJ formation}

In addition to $\mathrm{FtsK}_{\mathrm{c}}$, homologous recombination is necessary for full Xer recombination activity at dif, presum- ably because the reaction requires chromosomal dimers (Steiner and Kuempel 1998b; Recchia et al. 1999). We found that $\mathrm{HJ}$ formation at dif was not impaired in a $\mathrm{RecA}^{-}$strain or in a $\mathrm{RecF}^{-}$strain (Fig. 3E), in which homologous recombination is abolished or impaired, respectively. Homologous recombination on plasmids is mostly dependent on the recF pathway (Summers and Sherratt 1984; Kolodner et al. 1985), but neither recA nor $r e c F$ had any effect on $\mathrm{HJ}$ formation at a dif site carried by a plasmid (data not shown). We conclude that HJs are still formed by Xer recombination at dif in the absence of chromosome or plasmid dimers.

To confirm that chromosome dimer formation by homologous recombination is not necessary for synapsis and for the first pair of strand exchanges of the Xer recombination reaction, we monitored the level of HJs at dif in strains that should contain elevated numbers of chromosome dimers (Fig. 3F). UvrA ${ }^{-}$cells are deficient in nucleotide excision repair and therefore more heavily dependent on homologous recombination for the repair of DNA lesions; this should increase the probability of 
dimer formation and the need for Xer recombination. However, the level of $\mathrm{HJ}$ was not significantly increased in UvrA $^{-}$cells. There is a bias toward noncrossover events during homologous recombination in E. coli, thereby minimizing dimer formation. The bias appears to occur at the level of $\mathrm{HJ}$ resolution and requires RuvABC (Michel et al. 2000). In the absence of Ruv, the bias is lost and Xer recombination becomes important for survival (Michel et al. 2000). However, inactivating the $\operatorname{ruvA}$ gene did not increase the level of $\mathrm{HJ}$ detected at dif. This was also true for a $\mathrm{Rep}^{-} \mathrm{RuvA}^{-}$strain (data not shown), which relies on Xer recombination for its viability (Michel et al. 2000). No HJs were observed in a XerC ${ }^{-}$ RuvA $^{-}$strain (data not shown), confirming that the HJs we detected are due to Xer recombination and not to homologous recombination.

\section{$D A Z$ does not define a zone of competence for $\mathrm{HJ}$ formation}

The location of dif in a $\sim 30-\mathrm{kbp}$ zone of the E. coli chromosome, DAZ, is required for it to be an efficient substrate for a complete Xer recombination reaction (Tecklenburg et al. 1995; Cornet et al. 1996; Kuempel et al. 1996; Perals et al. 2000). To test if the location of dif in DAZ was important for synapsis and for the first pair of strand exchanges by XerCD, we compared the level of $\mathrm{HJ}$ in three strains carrying a single dif site at different locations in the chromosome. Displacing dif outside DAZ, $150 \mathrm{kbp}$ away from its original position, results in a 10 -fold decrease in its activity, as measured in a complete recombination reaction (Perals et al. 2000) but had only a $\sim$ twofold effect on HJ formation (Fig. 4A; cf. DAZ with zda 192; HJ levels are shown in the bottom panel). Thus, XerCD can form HJs at dif outside DAZ. However, displacing dif far from the replication terminus region, to within lacZ, resulted in a dramatic decrease in the level of HJs detected, although a positive signal was observed with overexposure of the blot. A likely explanation to this dramatic decrease is that the opportunities for synapsis of the two sister dif sites are limited by the rapid segregation of the chromosome immediately after replication when dif is outside the replication terminus region.

To confirm this hypothesis and rule out any effect of DAZ in HJ formation, we compared the level of HJs in strains carrying a tandem repeat of two dif sites inserted within DAZ or within lacZ (Fig. 4B). Because tandem repeats of dif within DAZ are unstable in $\mathrm{FtsK}_{\mathrm{c}}{ }^{+}$cells (Perals et al. 2000), levels of HJ formation were assayed in $\mathrm{FtsK}_{\mathrm{c}}{ }^{-}$cells in which the Xer recombination reaction does not go to completion. The level of HJs reached $7.3 \%$
A
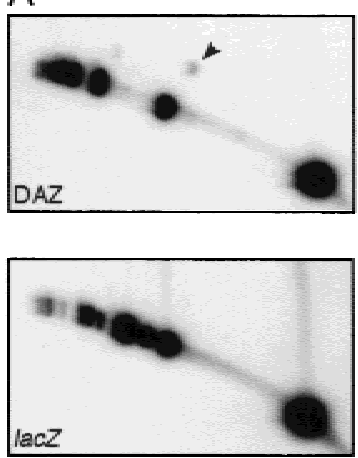

$\operatorname{lac} Z<0.01 \%$
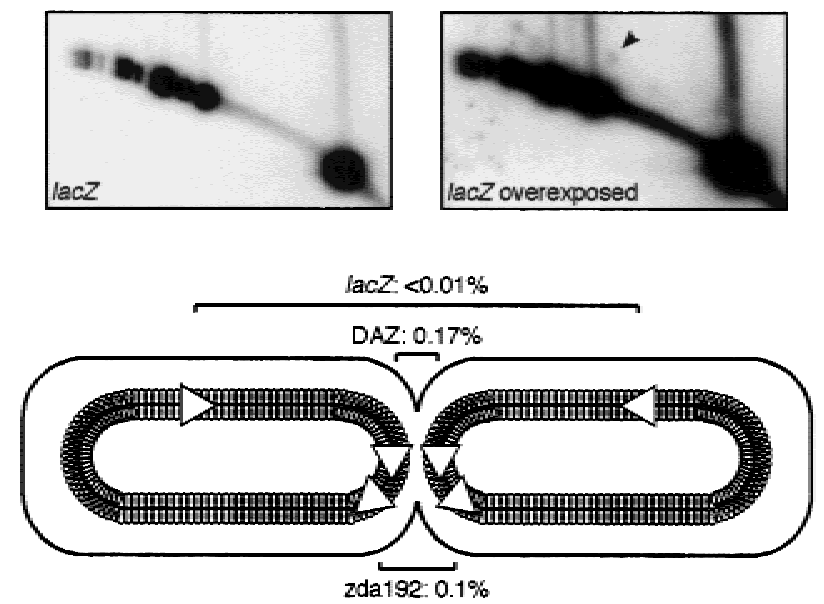
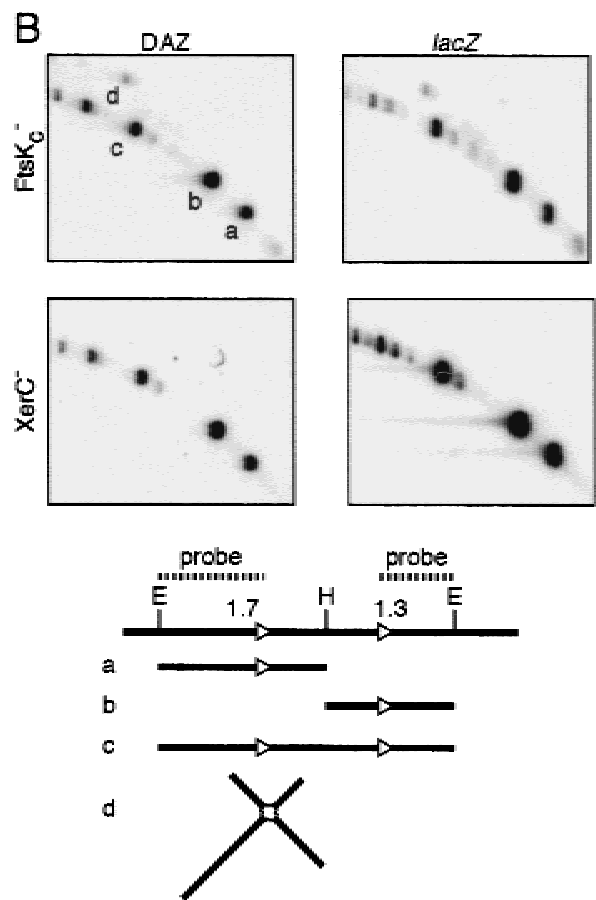

Figure 4. Effect of the location of dif on the level of HJs. (A) HJs at dif (indicated by arrowheads) were compared in three strains carrying a single site in DAZ (LN3080), at $150 \mathrm{~kb}$ to the left side of DAZ (zda192, LN3577) or at $1 \mathrm{Mb}$ to the right side of DAZ (lacZ, LN3091). The positions of the two sister dif sites in dividing cells are represented below the blots. Numbers indicate the relative intensity of the HJ spot to the intensity of the smaller linear fragment (mean of two independent experiments). (B) Increased and location-independent levels of $\mathrm{HJ}$ in cells carrying two tandem dif sites. $\mathrm{HJ}$ levels were compared in $\mathrm{FtsK}_{\mathrm{c}}{ }^{-}$and $\mathrm{XerC}^{-}$cells carrying a dif-Km-dif cassette in DAZ or in lacZ (FC313, FC354, FC235, FC284). EcoRV (E) and HindIII (H) were used to restrict DNA. The restriction digest map of the dif-Km-dif cassette and the molecules that can be attributed to the a, b, c, and d spots are represented below the blots. Note that the intensity of spot $d$ must be compared with the sum of the intensities of spot $a$ and $b$. 
when the directly repeated dif sites were located within DAZ (Fig. 4B, DAZ). This corresponds to a greater than 10 -fold increase when compared with strains with a single dif site. The observed HJs were due to Xer recombination because they were abolished in a $\mathrm{XerC}^{-}$background. The level of HJs remained high when the tandemly repeated dif sites were in lacZ $(4.4 \%)$, HJ formation being also entirely due to Xer recombination. Despite this high level of HJs, tandem repeats at lacZ are stable in $\mathrm{FtsK}^{+}$cells (data not shown). Thus, by providing a substrate in which two dif sites are readily accessible, we could overcome the need for dif to be located in the replication terminus region for $\mathrm{HJ}$ formation, but resolution to a complete recombinant product was still confined to DAZ.

\section{In vitro HJ formation by XerCD at dif}

We have shown that $\mathrm{HJ}$ formation at dif does not depend on chromosomal dimers, the location of dif in DAZ, or the activity of FtsK. Furthermore, $~ 5 \%$ of HJs were detected between tandemly repeated dif sites. This high level of HJs was surprising because only very low levels of HJs had been observed in previous in vitro experiments with purified Xer recombinases (Blakely et al. 2000; Colloms et al. 1996). In those experiments, the catalytic activity of XerC but not XerD was shown to be necessary.

We reasoned that in vitro synapsed dif sites might also undergo cycles of Xer-mediated strand exchanges that lead to the formation of HJs and their conversion back to substrate, but that this results in steady state levels of HJs too low to be readily detected. We therefore tested whether ethidium bromide (EtBr), which inhibits the action of type I topoisomerases and many other DNA processing enzymes, blocks the conversion of HJs back to substrate in in vitro reactions performed on a supercoiled plasmid carrying two dif sites, for example, by preferentially binding to HJ DNA and thereby inhibiting the action of XerCD on HJ intermediates. This would increase the level of HJs by displacing the equilibrium between $\mathrm{HJ}$ formation and resolution.

Addition of EtBr to in vitro reactions of XerCD with supercoiled DNA containing two directly repeated dif sites resulted in the detection of a high level of HJs, as confirmed by restriction analysis of the DNA with different enzymes (Fig. 5B). Forty percent glycerol was needed for maximum $\mathrm{HJ}$ detection (Fig. 5C,D). A time course experiment revealed that the level of HJs increased steadily in the plasmid population over time, and addition of $\mathrm{EtBr}$ at the beginning of the reaction had the same effect as addition of the $\mathrm{EtBr}$ at the end of the reaction (Fig. 5C, cf. the 20' time point in which EtBr was added first, to the $15^{\prime}$ point in which it was added after $\left.15^{\prime}\right)$. We conclude that synapsis is the rate limiting factor in the reaction rather than XerC-mediated strand exchanges. The increasing level of HJs with time therefore reflects the increasing number of synaptic complexes formed in the plasmid population.

To determine which recombinase was responsible for
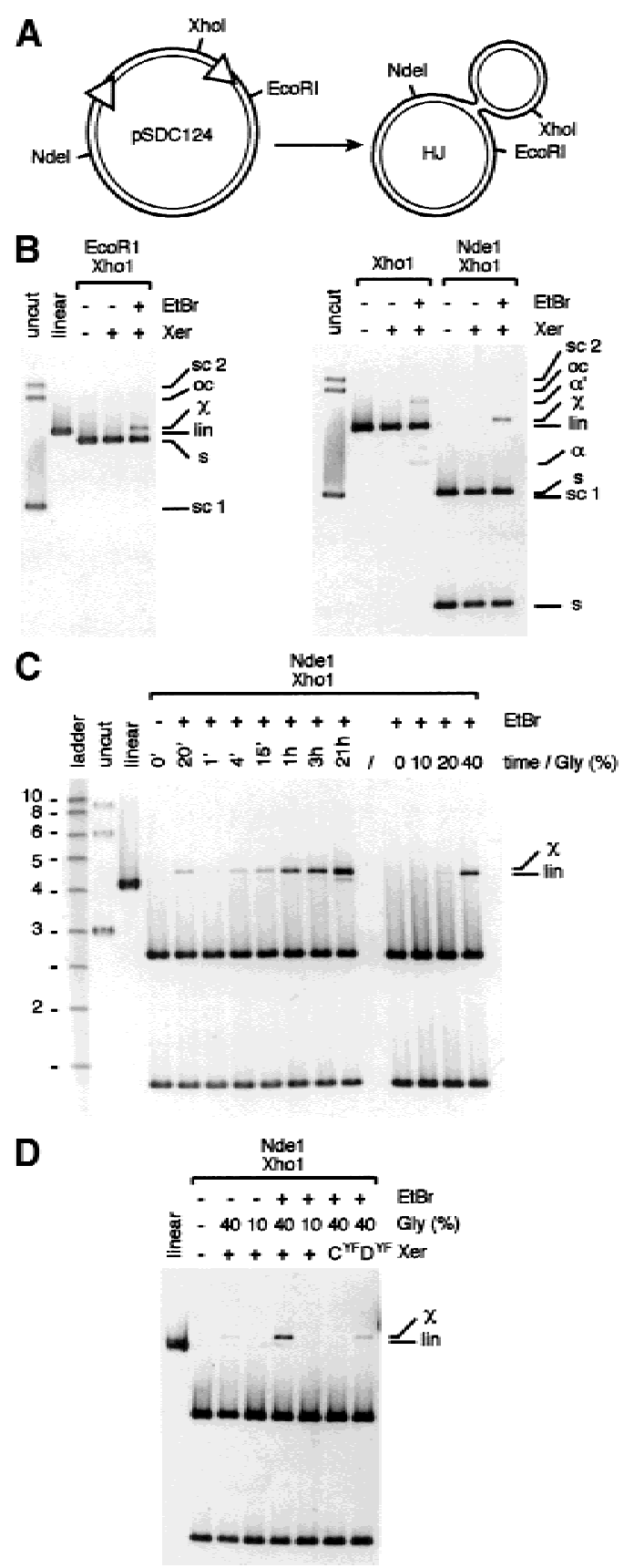

Figure 5. In vitro $\mathrm{HJ}$ formation by $\mathrm{XerCD}$ on a supercoiled plasmid carrying two dif sites. $(A)$ restriction map of plasmid pSDC124 and of the HJ created by action of XerCD. (B) Onehour reactions in $40 \%$ glycerol. (C) Time course experiment in $40 \%$ glycerol and effect of the glycerol concentration in 1-h reactions. Molecular weights are in kilobase pairs. $(D)$ Determination of the Xer recombinase whose catalytic activity is necessary for HJ formation. One-hour reactions in $40 \%$ glycerol used catalytically inactive mutants of $\mathrm{XerC}\left(\mathrm{C}^{\mathrm{YF}}\right)$ and $\mathrm{XerD}$ $\left(D^{\mathrm{YF}}\right)$ mixed with their functional partner. pSCD124 was left untreated (uncut, linear) or treated with the Xer recombinases (Xer). EtBr was added at the end of reactions as indicated. For the $20^{\prime}$ time point, EtBr was added at the beginning of the reaction. sc 1 , sc 2, lin, and oc, supercoiled monomer, supercoiled dimer, linear, open circle forms of pSDC124, respectively. s, restriction fragments from pSCD124; $\chi, \chi$-molecule containing a $\mathrm{HJ} ; \alpha$ and $\alpha^{\prime}$, supercoiled and nicked $\alpha$-molecules containing a HJ. 
the pair of strand exchanges that led to $\mathrm{HJ}$ formation, we performed the reactions by using catalytically inactive XerC and XerD mutants (Fig. 5D). No HJs were detected with the $\mathrm{XerC}^{\mathrm{YF}}$ mutant whereas they were still formed with the XerD ${ }^{\mathrm{YF}}$ mutant. Thus, the HJs observed result from strand exchanges mediated by the XerC recombinase, as suggested by previous experiments (Hallet et al. 1999; Blakely et al. 2000).

\section{Roles of DAZ and homologous recombination in Xer recombination}

We noted that overexpression of the 818 FtsK derivative resulted in an increase in plasmid resolution from $\sim 30 \%$ to $90 \%$ independently of the status of the homologous recombination system (Fig. 6A), and independently of DAZ because this was observed on a plasmid.

The dependence of Xer recombination at dif on the presence of chromosomal dimers is more obvious when the dif sites are in tandem repeat and positioned in chromosomal DAZ. Indeed, a $\mathrm{Km}^{\mathrm{R}}$ cassette placed between two tandem direct repeats of dif within DAZ is 10 times more stable in a RecA $A^{-}$strain than a $\operatorname{RecA}^{+}$strain, as a consequence of the difference in the levels of complete Xer recombination reactions (Fig. 6B). However, overexpression of the 818 protein increased dramatically the level of recombination at dif in both strains, so that there were no more differences in Xer recombination levels, as measured by $\mathrm{Km}^{\mathrm{R}}$ stability, between the $\mathrm{RecA}^{-}$and the RecA $\mathrm{A}^{+}$strains.

Integration of a plasmid carrying a single dif site into chromosomal dif by Xer recombination depends on the proper location of dif inside DAZ and on the $\mathrm{C}$ terminus of FtsK (Recchia et al. 1999). Displacing dif from DAZ to $1 a c Z$ decreases the integration frequency by $\sim 22.5$-fold (Fig. 6C). In the absence of $\mathrm{FtsK}_{\mathrm{c}}$, the remaining integration frequency decreases again to a 5.3-fold lower level. However, overexpression of the full-length FtsK protein (fl) or of the 818 protein restored the integration frequency to wild-type levels, irrespective of whether dif was in DAZ or in lacZ.

Thus, by overexpressing the C-terminal domain of FtsK so that it is distributed throughout the cell, we can overcome the dependence of Xer recombination at dif on conditions that generate chromosomal dimers (Fig. 6B) and on DAZ (Fig. 6C). We conclude that the influence of both homologous recombination and DAZ are linked to the spatial and temporal distribution of $\mathrm{FtsK}_{\mathrm{c}}$.

\section{Discussion}

XerC mediates cycles of strand exchange between substrate and HJ intermediate

Taken together, our in vivo and in vitro experiments provide strong support for the view that XerC continuously mediates the formation of HJs and their resolution back to initial substrate whenever the opportunity for synapsis between dif sites arises. We propose that this
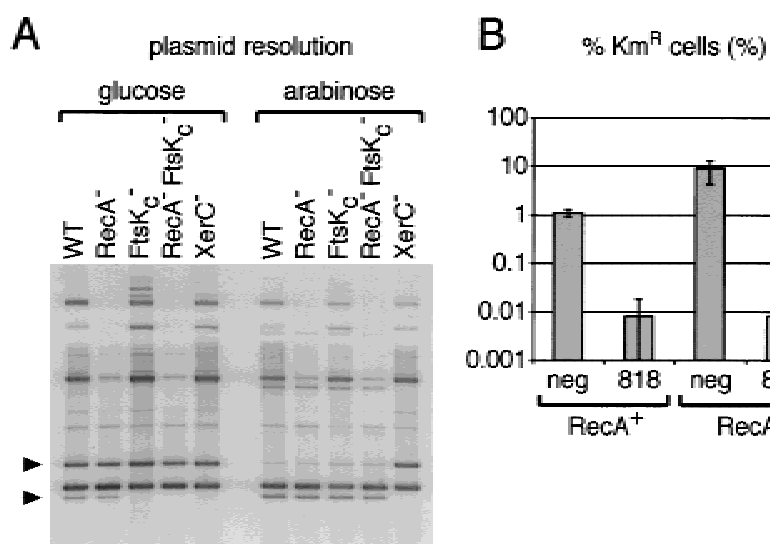

(\%) 29242111908876841

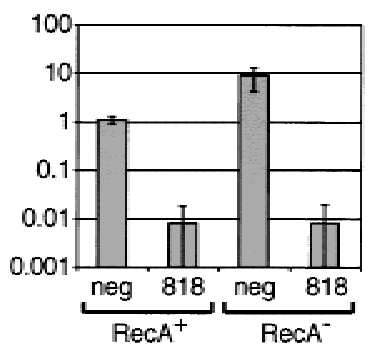

C

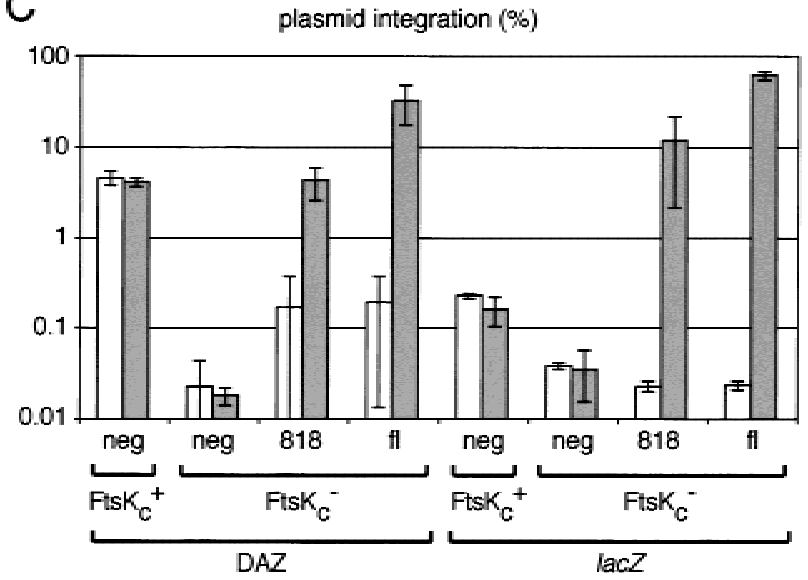

Figure 6. Overexpression of $\mathrm{FtsK}_{\mathrm{c}}$ abolishes the requirement for homologous recombination and for the location of dif in DAZ. (A) Plasmid resolution assay in WT (AB1157), RecA (GR19), FtsK ${ }_{\mathrm{c}}^{-}$(MA3), RecA ${ }^{-}$FtsK $_{\mathrm{c}}^{-}$(GR59), and XerC (DS8029) cells under conditions of repression (glucose) or induction (0.4\% arabinose) of 818 expression. The bands corresponding to the supercoiled substrate and supercoiled replicative product are indicated by the top and bottom black triangle, respectively. Numbers indicate the proportion of supercoiled product to total supercoiled substrate in each lane. (B) dif-Kmdif cassette resolution assay. $\operatorname{RecA}^{+}$(FC235) and $\mathrm{RecA}^{-}$(FC217) cells were transformed with a control expression vector (neg) or with the vector expressing the 818 FtsK derivative. They then were transformed with pFC225, which carries a functional xerC gene. The proportion of kanamycin resistant cells in the cultures $\left(\mathrm{Km}^{\mathrm{R}}\right)$ was quantitated after overnight growth in the presence of $0.2 \%$ arabinose. Results from a typical experiment are shown. (C) Plasmid integration assay. $\mathrm{FtsK}_{\mathrm{c}}{ }^{+}$and $\mathrm{FtsK}_{\mathrm{c}}{ }^{-}$cells carrying a single chromosomal dif site in DAZ or in lacZ (DS941, NL250, DS9041, MA2) were transformed with a control expression vector (neg), with the 818 expression vector or with the $\mathrm{fl}$ expression vector. They then were transformed with pFH127, which carries a single dif site. The proportion of cells having integrated this plasmid was quantitated after overnight growth at $30^{\circ} \mathrm{C}$ in the presence of glucose (white bars) or $0.2 \%$ arabinose (gray bars). Shown is the result of at least two independent experiments.

cycling continues from the time of synapsis immediately after dif replication until the time of chromosome seg- 
regation away from midcell and subsequent cell division some 10-20 min later. This process only requires the catalytic activity of XerC (Fig. 5) and is independent of the requirements for a complete Xer recombination reaction, in particular the activity of $\mathrm{FtsK}_{\mathrm{c}}$, conditions that influence the presence and level of chromosome dimers at the initiation of cell division, and the correct location of dif within DAZ (Figs. 3,4). The stability of synapsed dif sites in vivo may be facilitated by the cycles of XerCmediated $\mathrm{HJ}$ formation and resolution. Once formed, a synaptic complex is stable in vitro, and under appropriate $\mathrm{EtBr}$ treatment conditions, a substantial level of $\mathrm{HJ}$ intermediate can be detected (Fig. 5). Indeed, we now have an explanation of a previous puzzling observation: dif-containing $\mathrm{HJ}$ molecules are excellent recombination substrates (Arciszewska and Sherratt 1995) and XerCD bind more tightly to duplex dif than to the plasmid substrates cer and psi (Blake et al. 1997), which themselves undergo efficient recombination on supercoiled plasmids in vitro (Colloms et al. 1997). However, in the absence of $\mathrm{EtBr}$, XerCD appeared to generate no recombinant product and little or no HJs when they were reacted with a supercoiled molecule containing two dif sites (Colloms et al. 1996). Therefore, the presence of EtBr reveals the ability of XerCD to synapse dif sites and form HJs.

The presence of a stable synaptic complex between the two newly replicated sister dif sites may provide an answer to the potential problem of how two dif sites separated by more than $4 \mathrm{Mbp}$ in a dimeric chromosome find each other before Xer recombination. Nevertheless, a stable synaptic complex may impose some constraints on the local DNA topology. This could explain the apparent interaction between the Xer recombination system and topoisomerase IV, the dif site being a hot spot for Topo IV activity in vivo (Hojgaard et al. 1999). The presence of XerCD is necessary for this, but not FtsK or cell division, consistent with the effect being mediated at the HJ stage. Topo IV is required to remove any catenation of the newly replicated sister monomer chromosomes, before their segregation. Note that such catenation can be converted into knotting during formation of a dimeric chromosome. We propose that after replication Topo IV will remove all catenation/knotting other than the crossings entrapped in the Xer synaptic complex. These final crossings can only be removed when the XerCD synaptic complex has finally dissociated. It is this interaction that may have been assayed in the experiments of Hojgaard et al. (1999).

The C-terminal domain of FtsK is sufficient to support a complete $X e r$ recombination reaction at dif

Expression of the C-terminal domain of FtsK $\left(\mathrm{FtsK}_{\mathrm{c}}\right)$ restores Xer recombination between dif sites in $\mathrm{FtsK}_{\mathrm{c}}{ }^{-}$ cells (Fig. 1). The minimal domain necessary for complementation of Xer recombination at dif starts between amino acid residues 855 and 905 and ends between residues 1260 and 1329. Interestingly, the homology between domain 3 of FtsK and its homologs in other species starts at residue 839 at a predicted $\beta$-sheet and ends at residue 1323 , after a predicted $\alpha$-helix. The importance of the extreme $\mathrm{C}$ terminus of FtsK is underlined by our observation that proteins with Flag at their $\mathrm{C}$ terminus have decreased biological activity. Finally, the putative nucleotide binding site of FtsK was critical for its role in Xer recombination. It had been previously reported that two FtsK N-terminal truncations (starting at residue 825 and 863 ) fused to a polyhistidine tag (Boyle et al. 2000), and a protein containing domain 2 and 3 of FtsK (Recchia et al. 1999) did not complement Xer recombination at dif. However, we believe that these negative results may reflect a problem of expression or a lack of activity of the tagged proteins.

Overexpressing $\mathrm{FtsK}_{\mathrm{c}}$ increased the level of Xer recombination between dif sites carried by plasmids from $\sim 30 \%$ to $90 \%$ (Fig. 6A). It allowed Xer-mediated integration of a plasmid carrying a single dif site into chromosomal dif and rendered the reaction independent of the location of dif on the chromosome (Fig. 6C). Finally, it supported Xer recombination between two dif sites carried in tandem on the chromosome and rendered the reaction independent of conditions that lead to chromosomal dimers (Fig. 6B). We conclude that FtsK $_{\mathrm{c}}$ can activate Xer recombination independently of its location or of the location of dif in the cell, and that it can only activate Xer recombination on sites that are in its vicinity. Low, physiologically relevant, amounts of the fulllength FtsK protein are localized at the septum (Fig. 2A; Wang and Lutkenhaus 1998; Yu et al. 1998a). Therefore, multicopy plasmids, which are distributed throughout the cytoplasm (data not shown), may only access the C terminus of FtsK when they are located near the septum. Overexpression of the full-length FtsK protein, or of its C-terminal part, leads to an even distribution of the protein throughout the cell (Fig. 2A). Under these conditions, Xer recombination can then be activated by $\mathrm{FtsK}_{\mathrm{c}}$ whatever the location of dif.

Thus, our data support the view that $\mathrm{FtsK}_{\mathrm{c}}$ has a direct role in Xer recombination at dif. If its role were indirect, for example, by triggering a cascade of events leading to Xer activation, the unknown components of this cascade would have to be widely distributed and in excess amounts, because FtsK is the limiting factor in the Xer reaction.

Xer recombination at dif is controlled by FtsK at the XerD-mediated strand exchange step

Because the level of $\mathrm{HJ}$ formed in vivo at dif by XerCD is not influenced by the FtsK status of the cell (Fig. 3), FtsK must act after $\mathrm{HJ}$ formation, presumably by stimulating the second pair of strand exchanges mediated by XerD. Our previous work has led to a model in which a $\mathrm{HJ}$ conformational change is responsible for reciprocal activation of XerD and inactivation of XerC (Hallet et al. 1999; Recchia et al. 1999; Arciszewska et al. 2000). This is consistent with the observation that a recombinase variant combination that favors strand exchange by XerD can bypass the requirement for FtsK during recombination at dif (Recchia et al. 1999). We propose that 
FtsK $_{\mathrm{c}}$ is directly implicated in the change of conformation of the $\mathrm{HJ}$ intermediate by remodeling the local structure of the DNA in a DNA sequence-independent and ATP-dependent reaction. Precedents already exist for such processes. For example, HJ resolvases RuvC and T7 Endol switch their direction of resolution when catenation entrapped by a $\mathrm{HJ}$ is removed (Zerbib et al. 1997). Furthermore, PepA, which directs the geometry of the synaptic complexes during recombination at cer and $p s i$ (Colloms et al. 1997), is also required to facilitate the conformational change in the $\mathrm{HJ}$ formed by XerC to allow strand exchange by XerD (M. Robertson and D.J. Sherratt, unpubl.).

\section{Spatial distribution of $\mathrm{FtsK}_{c}$ and chromosome segregation}

We observed that the expression of the full-length FtsK protein could restore a wild-type phenotype to $\mathrm{FtsK}_{\mathrm{c}}{ }^{-}$ cells, whereas its overexpression led to filamentation (Fig. 2B). In addition, expression of the C-terminal domain had no effect on the morphology of $\mathrm{FtsK}_{\mathrm{c}}^{-}$cells. These observations correlate with the spatial distribution of the FtsK proteins inside the cell (Fig. 2A). We conclude that the preferential spatial localization of FtsK to the septum is critical for its role in chromosome segregation.

We propose that FtsK and DAZ are the two major components of a system designed to sense the presence of chromosome dimers at cell division, that is, to integrate information at the cellular level, and regulate on the basis of this information the activity of the Xer recombination machinery at the molecular level. DAZ could define a region of the chromosome that is actively maintained at midcell and thus is located close to the septum at cell division. Synaptic complex between dif sites in DAZ therefore would be the only ones that can be in contact with the C-terminal domain of wild-type FtsK. Supporting this idea, DAZ has been shown to stay preferentially localized at midcell in a strain containing a large chromosome inversion (Niki et al. 2000). As segregation of the chromosomes starts rapidly after replication, dif sites carried by monomeric chromosomes may be segregated away from each other before septum closure, therefore breaking the synaptic complex before access to septum-located FtsK is possible. In this case, only dif sites carried by a dimer will be accessible to FtsK. Thus, FtsK can be viewed as a molecular antenna that sits at the septum and activates the Xer recombination system when in the presence of a chromosome dimer.

In conclusion, our studies distinguish three important features of the Xer recombination reaction at dif. XerCD can form and resolve HJs back to substrate independently of any other cellular element. The $\mathrm{C}$ terminus of FtsK is sufficient to activate XerD, allowing intra- and intermolecular recombination reactions to go to completion. Finally, dif needs to be within a specific region of the chromosome, DAZ, and the C-terminal domain of FtsK needs to be correctly anchored (through its $\mathrm{N}$ terminus) at the septum for the Xer reaction to show direc- tionality, that is, to resolve dimers into monomers without risking the reverse reaction.

\section{Materials and methods}

Bacterial strains and plasmids

E. coli strains and plasmids are listed in Table 1. Deletions of ftsK were made by PCR and inserted into pBAD24. The lysine to alanine substitution of the $\mathrm{ATP}^{-}$mutant was generated by sitedirected mutagenesis. All constructions were verified by direct sequencing.

\section{Growth conditions}

Cells were grown in LB supplemented with thymine when necessary. M9 minimal medium containing $1 \%$ glucose and $0.5 \%$ casamino acids was used for cytological examination. Glucose $(1 \%)$ was used for repression of the arabinose promoter controlling the expression of the FtsK proteins. L-arabinose (as indicated) was added to media for induction.

In vivo plasmid resolution assays

Plasmid pFC238 carrying two dif sites was used as a substrate for in vivo resolution assays (Recchia et al. 1999).

\section{Immunohistochemistry}

Western analysis was performed using the M2 anti-Flag antibody (Sigma) and an ECF kit (Amersham). Blots were scanned on a Molecular Dynamics Fluorimager 575.

Cells were prepared for immunofluorescence as described previously (Pedersen et al. 1999). DAPI was used as a DNA staining agent. The M2 anti-Flag antibody was used as a first layer and an antimouse antibody coupled to fluorescein as a second layer. Phase-contrast and fluorescent images were acquired using a cooled CCD camera (Princeton Instruments) and Metamorph image acquisition software (Universal Imaging Corporation) from an Olympus BX60 fluorescence microscope.

\section{D gel electrophoresis and hybridization}

Ten milliliters of exponentially growing cells was collected by centrifugation, washed in PBS, and resuspended in a solution of $100 \mu \mathrm{g} / \mathrm{mL} \mathrm{4,5',8-trimethylpsoralen} \mathrm{(Sigma)} \mathrm{and} \mathrm{20 \%} \mathrm{ethanol} \mathrm{in}$ PBS. Cells were exposed to UV light ( $\left.365 \mathrm{~nm}, 40 \mathrm{~kJ} / \mathrm{m}^{2}\right)$ by using a Stratalinker (Stratagene). Cross-linking extent was measured by the ability of cross-linked DNA to renature under conditions of RAGE analysis (Barre et al. 2000), as well as by the inhibition of cleavage of the EcoRV restriction enzyme. The first dimension of electrophoresis was performed at $0.5 \mathrm{~V} / \mathrm{cm}$ in a $0.7 \%$ agarose TBE gel. The second dimension was performed at 5 $\mathrm{V} / \mathrm{cm}$ at $4^{\circ} \mathrm{C}$ in a $1.2 \%$ agarose TBE gel containing $0.3 \mu \mathrm{g} / \mathrm{mL}$ of ethidium bromide. DNA was alkali transferred onto a Hybond- $\mathrm{N}^{+}$membrane (Amersham). Hybridization was performed using ${ }^{32} \mathrm{P}$-probes labeled with a random priming kit (Roche) in Church buffer. DNA species were visualized after exposure to blue sensitive X-ray films (Kodak) with one intensifying screen for $0.2-3$ wk at $-70^{\circ} \mathrm{C}$. They were quantitated using a Molecular Dynamic PhosphorImager and the ImageQuant software (Molecular Dynamics).

\section{In vitro $H J$ formation on plasmids}

In vitro reactions were performed in $50 \mathrm{mM}$ Tris $(\mathrm{pH} 7.5), 50$ $\mathrm{mM} \mathrm{NaCl}, 5 \mathrm{mM}$ spermidine, $2 \mathrm{mM}$ EDTA, $0.1 \mathrm{mM}$ DTT, 10 
Barre et al.

Table 1. Strains and plasmids

\begin{tabular}{|c|c|c|}
\hline Strain & Relevant genotype & Source/reference \\
\hline $\mathrm{AB} 1157$ & $\mathrm{Rec}^{+}$laboratory strain & Summers and Sherratt 1988 \\
\hline DS941 & $\mathrm{AB} 1157 \mathrm{recF}$ & Summers and Sherratt 1988 \\
\hline DS9041 & DS941 ftsK:: $\mathrm{Cm}^{R}$ & Recchia et al. 1999 \\
\hline DS8029 & $\mathrm{AB} 1157$ xerC $:: \mathrm{Km}^{R}$ & G. Blakely \\
\hline GR18 & $\mathrm{AB} 1157 \mathrm{xer}:: \mathrm{Km}^{R}$ & G. Recchia \\
\hline MA3 & $\mathrm{AB} 1157 \mathrm{ftsK}:: \mathrm{Cm}^{R}$ & Recchia et al. 1999 \\
\hline GR19 & $\mathrm{AB} 1157 \mathrm{rec} A:: \mathrm{Cm}^{R}$ & Recchia et al. 1999 \\
\hline N3137 & AB1157 uvrA::Tn10 & McGlynn and Lloyd 2000 \\
\hline JJC40 & $\mathrm{AB} 1157 h s d R$ & Seigneur et al. 1998 \\
\hline JJC662 & JJC40 ruvA60:: Tn10 & Michel et al. 2000 \\
\hline JJC494 & JJC662 $\Delta$ rep $:: \mathrm{Km}^{R}$ & Seigneur et al. 1998 \\
\hline JJC733 & JJC662 xerC $:: \mathrm{Km}^{R}$ & Michel et al. 2000 \\
\hline LN3080 & LN2666 (thy $\left.{ }^{-}\right)$dif in DAZ & Cornet et al. 1996 \\
\hline LN3091 & LN2666 dif in LacZ & Perals et al. 2000 \\
\hline LN3577 & LN2666 dif in zda192 & Perals et al. 2000 \\
\hline FC313 & AB1157 ftsK dif-Km-dif in DAZ & F. Cornet \\
\hline FC354 & $\mathrm{AB} 1157$ ftsK dif-Km-dif in lacZ & F. Cornet \\
\hline FC235 & LN2666 xerC dif-Km-dif in DAZ & F. Cornet \\
\hline FC284 & LN2666 xerC dif-Km-dif in lacZ & F. Cornet \\
\hline GR59 & MA3 recA56 srl::Tn10 & Recchia et al. 1999 \\
\hline FC217 & FC235 recA & F. Cornet \\
\hline NL250 & DS941 dif $\Delta 6$ dif in lacZ & Leslie and Sherratt 1995 \\
\hline MA2 & NL250 ftsK & Recchia et al. 1999 \\
\hline Plasmid & Description & Source/reference \\
\hline pBAD24 & Expression vector & Guzman et al. 1995 \\
\hline pFX83 & Flag fusion vector & This study \\
\hline pFX88 & fl FtsK N-terminally tagged & This study \\
\hline pFX89 & $734 \mathrm{~N}$-terminally tagged & This study \\
\hline pFX90 & $818 \mathrm{~N}$-terminally tagged & This study \\
\hline pFX91 & $855 \mathrm{~N}$-terminally tagged & This study \\
\hline pFX99 & $906 \mathrm{~N}$-terminally tagged & This study \\
\hline pFX101 & $1260 \mathrm{~N}$-terminally tagged & This study \\
\hline pFX102 & $\mathrm{ATP}^{-} \mathrm{N}$-terminally tagged & This study \\
\hline pSDC124 & pUC18-based dif reporter & Blakely et al. 1991 \\
\hline pFC238 & pGB2-based dif reporter & Recchia et al. 1999 \\
\hline pFH127 & pGB2ts carrying one dif site & Hayes and Sherratt 1997 \\
\hline pFC225 & p15a-based XerC expression vector & F. Cornet \\
\hline
\end{tabular}

DAZ, dif activity zone; fl, full length.

$\mu \mathrm{g} / \mathrm{mL}$ BSA, and glycerol (as indicated). Ethidium bromide $(0.25$ $\mathrm{mg} / \mathrm{mL}$ final concentration) was used to trap HJ intermediates. Reactions were stopped by extraction with phenol. The supercoiled substrate and the XerC and XerD recombinases were purified as described elsewhere (Colloms et al. 1996).

\section{Plasmid integration assays}

The level of intermolecular recombination between a plasmidborne dif site and a chromosomal dif site was assayed as described previously (Leslie and Sherratt 1995; Hayes and Sherratt 1997).

\section{dif-Km-dif cassette resolution assays}

$\mathrm{XerC}^{-}$strains carrying chromosomal insertions of the dif- Kmdif cassette were induced for dif recombination by transformation with the XerC expression vector pFC225, which carries a spectinomycin resistance cassette. After overnight growth, the percentage of kanamycin-resistant bacteria was determined by plating serial dilutions on spectinomycin plates with or without kanamycin.

\section{Acknowledgments}

We thank H. Capiaux, B. Lloyd, and B. Michel for the kind gift of strains; N. Hunter and V. Regnier for technical advice; M. Chandler and J. Roth for helpful discussions. M.A. was supported by an MRC studentship, A.H. by a Socrates award, and F.-X.B. by ARC and EMBO fellowships. S.D.C is supported by a Wellcome Trust Senior Fellowship. D.J.S. is supported by the Wellcome Trust.

The publication costs of this article were defrayed in part by payment of page charges. This article must therefore be hereby marked "advertisement" in accordance with 18 USC section 1734 solely to indicate this fact.

\section{References}

Arciszewska, L.K. and Sherratt, D.J. 1995. Xer site-specific recombination in vitro. EMBO J. 14: 2112-2120. 
Arciszewska, L.K., Baker, R.A., Hallet, B., and Sherratt, D.J. 2000. Coordinated control of XerC and XerD catalytic activities during Holliday junction resolution. J. Mol. Biol. 299: 391-403.

Austin, S., Ziese, M., and Sternberg, N. 1981. A novel role for site-specific recombination in maintenance of bacterial replicons. Cell 25: 729-736.

Barre, F.X., Ait-Si-Ali, S., Giovannangeli, C., Luis, R., Robin, P., Pritchard, L.L., Helene, C., and Harel-Bellan, A. 2000. Unambiguous demonstration of triple-helix-directed gene modification. Proc. Natl. Acad. Sci. 97: 3084-3088.

Begg, K.J., Dewar, S.J., and Donachie, W.D. 1995. A new Escherichia coli cell division gene, ftsK. J. Bacteriol. 177: 62116222.

Blake, J.A., Ganguly, N., and Sherratt, D.J. 1997. DNA sequence of recombinase-binding sites can determine Xer site-specific recombination outcome. Mol. Microbiol. 23: 387-398.

Blakely, G., Colloms, S., May, G., Burke, M., and Sherratt, D. 1991. Escherichia coli XerC recombinase is required for chromosomal segregation at cell division. New Biol. 3: 789798.

Blakely, G., May, G., McCulloch, R., Arciszewska, L.K., Burke, M., Lovett, S.T., and Sherratt, D.J. 1993. Two related recombinases are required for site-specific recombination at dif and cer in E. coli K12. Cell 75: 351-361.

Blakely, G.W., Davidson, A.O., and Sherratt, D.J. 2000. Sequential strand exchange by XerC and XerD during site-specific recombination at dif. J. Biol. Chem. 275: 9930-9936.

Boyle, D.S., Grant, D., Draper, G.C., and Donachie, W.D. 2000. All major regions of FtsK are required for resolution of chromosome dimers. J. Bacteriol. 182: 4124-4127.

Clerget, M. 1991. Site-specific recombination promoted by a short DNA segment of plasmid R1 and by a homologous segment in the terminus region of the Escherichia coli chromosome. New Biol. 3: 780-788.

Colloms, S.D., Sykora, P., Szatmari, G., and Sherratt, D.J. 1990. Recombination at ColE1 cer requires the Escherichia coli xerC gene product, a member of the lambda integrase family of site-specific recombinases. J. Bacteriol. 172: 6973-6980.

Colloms, S.D., McCulloch, R., Grant, K., Neilson, L., and Sherratt, D.J. 1996. Xer-mediated site-specific recombination in vitro. EMBO J. 15: 1172-1181.

Colloms, S.D., Bath, J., and Sherratt, D.J. 1997. Topological selectivity in Xer site-specific recombination. Cell 88: 855864.

Cornet, F., Louarn, J., Patte, J., and Louarn, J.M. 1996. Restriction of the activity of the recombination site dif to a small zone of the Escherichia coli chromosome. Genes \& Dev. 10: $1152-1161$.

Cox, M.M., Goodman, M.F., Kreuzer, K.N., Sherratt, D.J., Sandler, S.J., and Marians, K.J. 2000. The importance of repairing stalled replication forks. Nature 404: 37-41.

Diez, A.A., Farewell, A., Nannmark, U., and Nystrom, T. 1997. A mutation in the ftsK gene of Escherichia coli affects cellcell separation, stationary-phase survival, stress adaptation, and expression of the gene encoding the stress protein UspA. J. Bacteriol. 179: 5878-5883.

Dorazi, R. and Dewar, S.J. 2000. Membrane topology of the Nterminus of the Escherichia coli FtsK division protein. FEBS Lett. 478: 13-18.

Draper, G.C., McLennan, N., Begg, K., Masters, M., and Donachie, W.D. 1998. Only the N-terminal domain of FtsK functions in cell division. J. Bacteriol. 180: 4621-4627.

Guzman, L.M., Belin, D., Carson, M.J., and Beckwith, J. 1995. Tight regulation, modulation, and high-level expression by vectors containing the arabinose pBAD promoter. I. Bacte- riol. 177: 4121-4130.

Hallet, B., Arciszewska, L.K., and Sherratt, D.J. 1999. Reciprocal control of catalysis by the tyrosine recombinases XerC and XerD: An enzymatic switch in site-specific recombination. Mol. Cell 4: 949-959.

Hayes, F. and Sherratt, D.J. 1997. Recombinase binding specificity at the chromosome dimer resolution site dif of Escherichia coli. J. Mol. Biol. 266: 525-537.

Hendricks, E.C., Szerlong, H., Hill, T., and Kuempel, P. 2000. Cell division, guillotining of dimer chromosomes and SOS induction in resolution mutants (dif, xerC and xerD) of Escherichia coli. Mol. Microbiol. 36: 973-981.

Hojgaard, A., Szerlong, H., Tabor, C., and Kuempel, P. 1999. Norfloxacin-induced DNA cleavage occurs at the dif resolvase locus in Escherichia coli and is the result of interaction with topoisomerase IV. Mol. Microbiol. 33: 1027-1036.

Kolodner, R., Fishel, R.A., and Howard, M. 1985. Genetic recombination of bacterial plasmid DNA: Effect of RecF pathway mutations on plasmid recombination in Escherichia coli. J. Bacteriol. 163: 1060-1066.

Kuempel, P.L., Henson, J.M., Dircks, L., Tecklenburg, M., and Lim, D.F. 1991. dif, a recA-independent recombination site in the terminus region of the chromosome of Escherichia coli. New Biol. 3: 799-811.

Kuempel, P., Hogaard, A., Nielsen, M., Nagappan, O., and Tecklenburg, M. 1996. Use of a transposon (Tndif) to obtain suppressing and nonsuppressing insertions of the dif resolvase site of Escherichia coli. Genes \& Dev. 10: 1162-1171.

Leslie, N.R. and Sherratt, D.J. 1995. Site-specific recombination in the replication terminus region of Escherichia coli: Functional replacement of dif. EMBO J. 14: 1561-1570.

Liu, G., Draper, G.C., and Donachie, W.D. 1998. FtsK is a bifunctional protein involved in cell division and chromosome localization in Escherichia coli. Mol. Microbiol. 29: 893-903.

McGlynn, P. and Lloyd, R.G. 2000. Modulation of RNA polymerase by (p)ppGpp reveals a RecG-dependent mechanism for replication fork progression. Cell 101: 35-45.

Michel, B. 2000. Replication fork arrest and DNA recombination. Trends Biochem. Sci. 25: 173-178.

Michel, B., Recchia, G.D., Penel-Colin, M., Ehrlich, S.D., and Sherratt, D.J. 2000. Resolution of Holliday junctions by RuvABC prevents dimer formation in rep mutants and UV irradiated cells. Mol. Microbiol. 37: 181-191.

Niki, H., Yamaichi, Y., and Hiraga, S. 2000. Dynamic organization of chromosomal DNA in Escherichia coli. Genes \& Dev. 14: 212-223.

Pedersen, L.B., Angert, E.R., and Setlow, P. 1999. Septal localization of penicillin-binding protein 1 in Bacillus subtilis. J. Bacteriol. 181: 3201-3211.

Perals, K., Cornet, F., Merlet, Y., Delon, I., and Louarn, J.M. 2000. Functional polarization of the Escherichia coli chromosome terminus: The dif site acts in chromosome dimer resolution only when located between long stretches of opposite polarity. Mol. Microbiol. 36: 33-43.

Recchia, G.D. and Sherratt, D.J. 1999. Conservation of Xer sitespecific recombination genes in bacteria. Mol. Microbiol. 34: 1146-1148.

Recchia, G.D., Aroyo, M., Wolf, D., Blakely, G., and Sherratt, D.J. 1999. FtsK-dependent and -independent pathways of Xer site-specific recombination. EMBO J. 18: 5724-5734.

Schwacha, A. and Kleckner, N. 1994. Identification of joint molecules that form frequently between homologs but rarely between sister chromatids during yeast meiosis. Cell 76: $51-$ 63.

Schwacha, A. and Kleckner, N. 1995. Identification of double 
Barre et al.

Holliday junctions as intermediates in meiotic recombination. Cell 83: 783-791.

Seigneur, M., Bidnenko, V., Ehrlich, S.D., and Michel, B. 1998. RuvAB acts at arrested replication forks. Cell 95: 419-430.

Steiner, W.W. and Kuempel, P.L. 1998a. Cell division is required for resolution of dimer chromosomes at the dif locus of Escherichia coli. Mol. Microbiol. 27: 257-268.

Steiner, W.W. and Kuempel, P.L. 1998b. Sister chromatid exchange frequencies in Escherichia coli analyzed by recombination at the dif resolvase site. J. Bacteriol. 180: 6269-6275.

Steiner, W., Liu, G., Donachie, W.D., and Kuempel, P. 1999. The cytoplasmic domain of FtsK protein is required for resolution of chromosome dimers. Mol. Microbiol. 31: 579-583.

Summers, D.K. and Sherratt, D.J. 1984. Multimerization of high copy number plasmids causes instability: CoIE1 encodes a determinant essential for plasmid monomerization and stability. Cell 36: 1097-1103.

Summers, D.K. and Sherratt, D.J. 1988. Resolution of ColE1 dimers requires a DNA sequence implicated in the threedimensional organization of the cer site. EMBO J. 7: 851858.

Tecklenburg, M., Naumer, A., Nagappan, O., and Kuempel, P. 1995. The dif resolvase locus of the Escherichia coli chromosome can be replaced by a 33-bp sequence, but function depends on location. Proc. Nat1. Acad. Sci. 92: 1352-1356.

Wang, L. and Lutkenhaus, J. 1998. FtsK is an essential cell division protein that is localized to the septum and induced as part of the SOS response. Mol. Microbiol. 29: 731-740.

Wu, L.J., Lewis, P.J., Allmansberger, R., Hauser, P.M., and Errington, J. 1995. A conjugation-like mechanism for prespore chromosome partitioning during sporulation in Bacillus subtilis. Genes \& Dev. 9: 1316-1326.

Yu, X.C., Tran, A.H., Sun, Q., and Margolin, W. 1998a. Localization of cell division protein FtsK to the Escherichia coli septum and identification of a potential $\mathrm{N}$-terminal targeting domain. J. Bacteriol. 180: 1296-1304.

Yu, X.C., Weihe, E.K., and Margolin, W. 1998b. Role of the C terminus of FtsK in Escherichia coli chromosome segregation. J. Bacteriol. 180: 6424-6428.

Zerbib, D., Colloms, S.D., Sherratt, D.J., and West, S.C. 1997. Effect of DNA topology on Holliday junction resolution by Escherichia coli RuvC and bacteriophage T7 endonuclease I. J. Mol. Biol. 270: 663-673. 


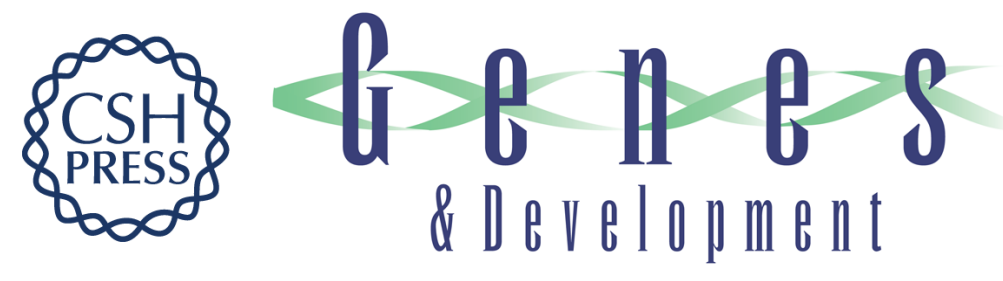

\section{FtsK functions in the processing of a Holliday junction intermediate during bacterial chromosome segregation}

François-Xavier Barre, Mira Aroyo, Sean D. Colloms, et al.

Genes Dev. 2000, 14:

Access the most recent version at doi:10.1101/gad.188700

References This article cites 51 articles, 19 of which can be accessed free at: http://genesdev.cshlp.org/content/14/23/2976.full.html\#ref-list-1

License

Email Alerting

Receive free email alerts when new articles cite this article - sign up in the box at the top Service right corner of the article or click here.

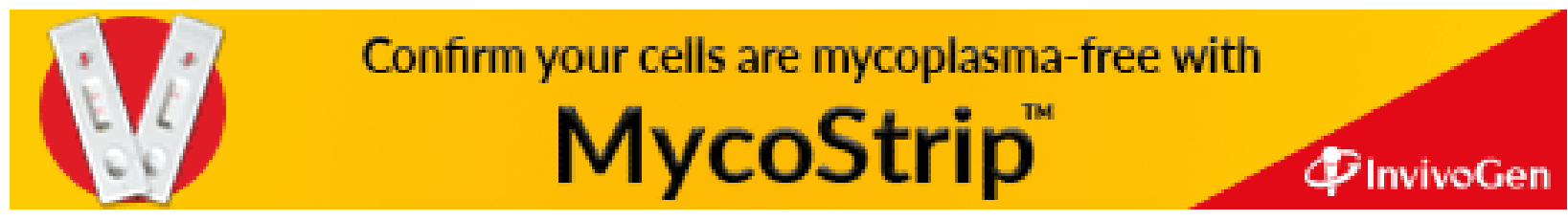

